\title{
Effects of elevated temperatures on the properties of nanomodified rapid hardening concretes
}

\author{
Uliana Marushchak ${ }^{1, *}$, Myroslav Sanytsky ${ }^{1}$, and Yuriy Olevych ${ }^{1}$ \\ ${ }^{1}$ Lviv Polytechnic National University, Building Production Department, S. Bandera str. 12, 79013, \\ Lviv, Ukraine
}

\begin{abstract}
Effects of elevated temperature exposure and hardening age on mechanical properties of nanomodified concrete are presented. The mass loss, compressive strength and shrinkage of the exposed to the elevated temperatures and cooled specimens were determined. Nanomodification by ultrafine mineral additives and polycarboxylate eter superplasticizer provides direct early structure formation, higher strength at early and later ages, and improved thermal resistance in a range of $200-350{ }^{\circ} \mathrm{C}$ of cementbase materials. High specific surface area of ultrafine mineral additive particles and their "excess surface energy" determine interaction degree with powder part components of concrete and allow realizing dense packing, filler, high water-reducing, early pozzolanic reaction, high early strength effects to increasing the rigidity of the cement matrix to resist deformation at impact of elevated temperature.
\end{abstract}

\section{Introduction}

The improving of the reliability of buildings and structures including traffic, tunnel structures and fortifications, which exposed to fire and high temperatures, ensures their safe exploitation. Exposure to elevated temperatures significantly affects the performance of concrete structures, since concrete is not stable at high temperatures. Subjecting concrete to a higher temperature leads to severe deterioration and it undergoes a number of transformations and reactions, thereby causing progressive breakdown of cement gel structure, reduced durability, increased tendency of drying shrinkage, and structural cracking $[1,2]$. Strict requirements regarding the resistance of structures to fire and elevated temperatures, have forced to develop new solutions to improve existing cementbased materials due to the designing of thermal stable high strength concrete. The use of such concrete for repairing works on intensive traffic zones, roads, facilities in airports and railways sets high requirements concerning hardening time.

One of the innovative ways to obtain rapid-hardening concretes with high performance is the use of nanotechnology techniques related to the directed process of structure formation by modification with nanoscale elements [3, 4]. The increasing of thermal stability of paste matrix can be achieved by adding ultrafine supplementary cementitious

* Corresponding author: ulmarushchak@ukr.net 
materials. The ultrafine particles less than $1 \mu \mathrm{m}$ (nanostructure scale), which have defined a supply of free surface energy, increase the interfacial surface that can accelerate chemical reactions, detect catalytic activity and cause more substantial influence of superficial atoms on synthesis of cementitious system strength. The ultrafine particles become an integrated part of the hydrated cement paste and improve homogeneity of the interfacial zone.

Cement pastes modified with nanosilica showed that the nanosilica exhibited increased thermal stability. This effect can be attributed to improvement of thermal stability of calcium silicate hydrate gel $(\mathrm{C}-\mathrm{S}-\mathrm{H})$ and to the filler effect [5]. Due to the reactivity of nanosilica more high-density $\mathrm{C}-\mathrm{S}-\mathrm{H}$ was produced, and samples containing nanosilica had still higher residual compressive strength. Presence of nanosilica contributes to reduction of micro-cracks due to its pozzolanic activity [6]. One of the widely used methods of concrete nanotechnology is the modification with the surface active substances and ultrafine additives. Highly efficient polycarboxylate superplasticizers with the nano-designed molecular chains make it possible to increase strength and decrease surface spalling due to significant reduction of the water-cement ratio [7]. The development of rapid hardening concretes with high thermal resistance requires complex nanomodification of cement matrix by ultrafine supplementary material and effective polycarboxylate superplasticizers.

\section{Materials and methods}

\subsection{Materials}

Ordinary Portland cement CEM I 42.5 (according to EN 197-1 standard) was used in the investigations. Natural sand of Zhovkva quarry $(\mathrm{MF}=2.1)$ and coarse aggregate fractions 2$5 \mathrm{~mm}$ were used for fine-grained concrete production. Low calcium fly ash, silica fume and methakaoline were used as ultrafine supplementary cementitious materials. The dosages of polycarboxylate eter superplasticizer GLENIUM ACE 430 (PCE) which incorporated into nanomodified mixes was $1.5 \%$ by weight of cement. The nanomodified cement containing ultrafine mineral additives, polycarboxylate superplasticizer are characterized by the gapgraded particle size distribution which leads to the best packing density of particles.

\subsection{Preparation of the specimens and testing}

Consistency of fresh concrete was determined by flow-table method conforming to EN 1015-3 standard. The fine-grained concrete components were mixed according to EN 196-1 procedure. The samples $40 \mathrm{~mm}$ x $40 \mathrm{~mm} \times 160 \mathrm{~mm}$ were cured in normal conditions for the hardening of concrete $\left(90-100 \% \mathrm{RH}\right.$ at $\left.20 \pm 2^{\circ} \mathrm{C}\right)$. After 1,2 and 7 days the samples were dried in a chamber at a constant temperature of $105^{\circ} \mathrm{C}$. Then some specimens were kept in medium-temperature furnace and subjected to elevated temperatures of $200^{\circ} \mathrm{C}$ and $350^{\circ} \mathrm{C}$ for 2 hours according to DSTU B.V.2.7-249:2011. After cooling, samples underwent the compressive strength tests according to EN 196-1. Weight loss and shrinkage of concrete were determined after exposure to elevated temperatures.

\section{Result and discussion}

The consistencies of reference fresh mixture (RC) and nanomodified fresh mixtures (NMC) determined by the flow table method are 180-190 mm. However nanomodified finegrained mixture characterizes significant water-reduction effect $\Delta \mathrm{W} / \mathrm{C}=32 \%$.

The early strength of nanomodified fine-grained concrete after 1 day is $33.3 \mathrm{MPa}$ and after 2 days $-58.4 \mathrm{MPa}$ that is, respectively, 1.9 and 2.33 time higher than the strength of 
reference concrete (Fig. 1). The compressive strength of nanomodified fine-grained concrete after 28 days of hardening at normal conditions increases up to $104 \mathrm{MPa}$. The parameter $\mathrm{R}_{\mathrm{c} 2} / \mathrm{R}_{\mathrm{c} 28}$ of nanomodified concrete is $66.9 \%$, which allows attributing these concrete to rapid hardening high strength concretes.

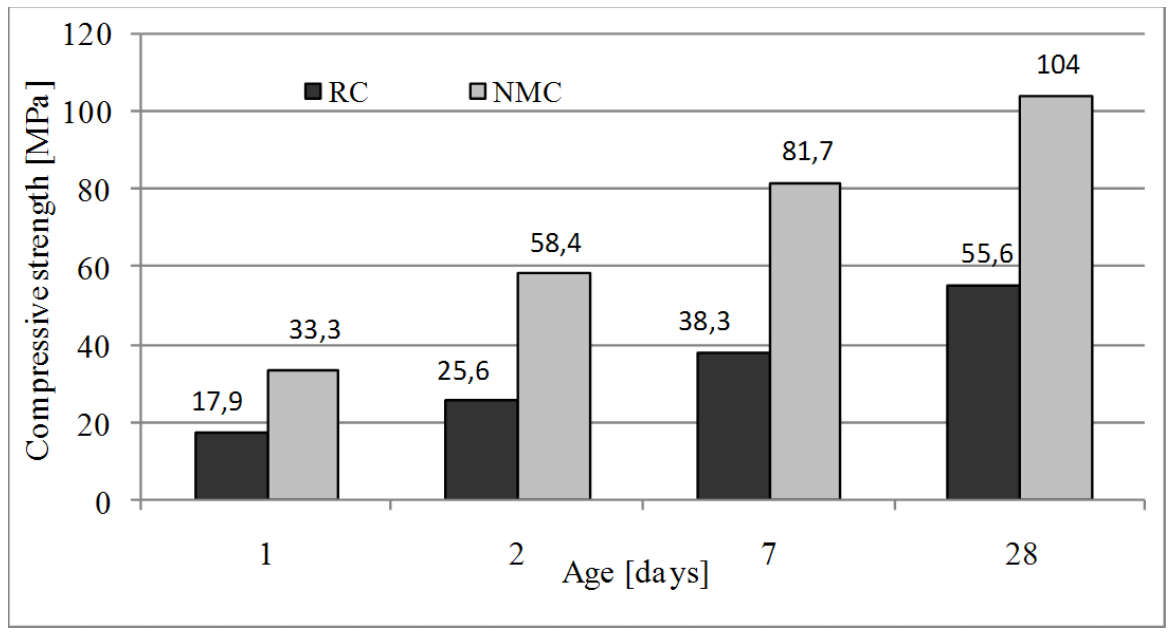

Fig. 1. Compressive strength of fine-grained concrete in normal condition.

Up to $350^{\circ} \mathrm{C}$ the strength of heat-treated samples was still higher than those of the control samples (Fig. 2). Thus, the strength of nanomodified fine-grained concrete after 1 day hardening in normal conditions and exposure to $200^{\circ} \mathrm{C}$ increases 2.6 times compared to reference concrete. The strength increasing of nanomodified concrete after 2 days when exposed to $200^{\circ} \mathrm{C}$ is $47.6 \%$, and after 7 days $-13.5 \%$.

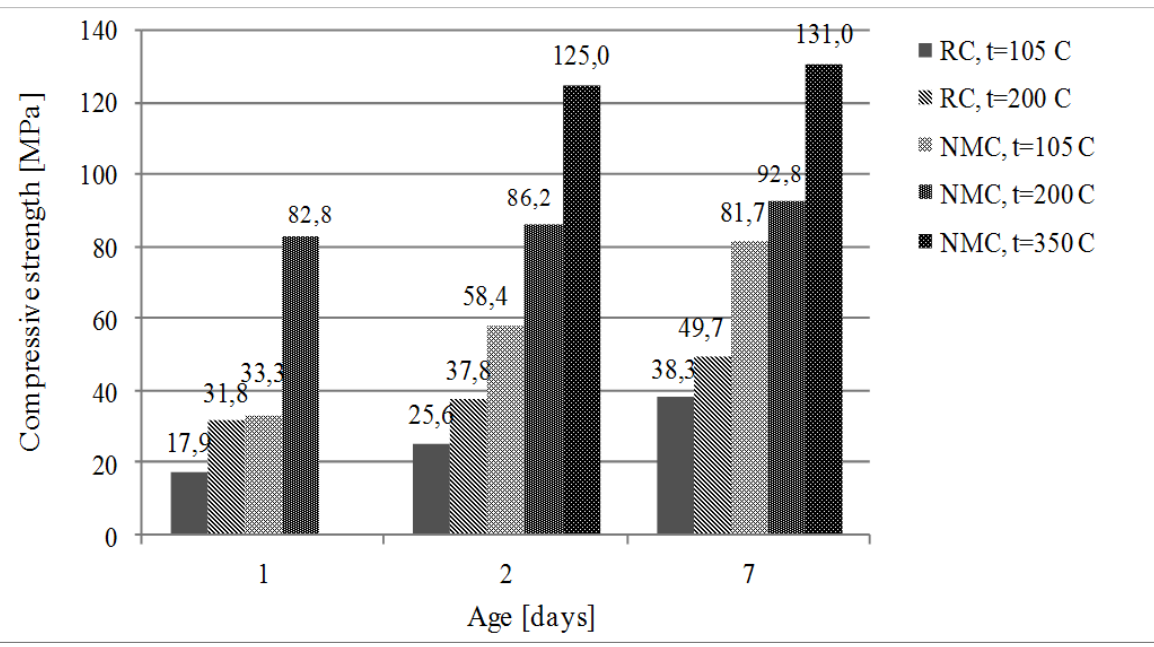

Fig. 2. Residual compressive strength of fine-grained concrete subjected to elevated temperature.

After exposure to $350^{\circ} \mathrm{C}$ and subsequent cooling to room temperature, there was a significant improvement in strength for samples of nanomodified fine-grained concrete. Thus, strength of nanomodified concrete after 2 and 7 days of hardening at normal condition is, respectively, 125.0 and $131.0 \mathrm{MPa}$. The reason is that among a certain higher temperature range, the pore pressure in the hardened cement mortar is increased by the evaporation of internal water, forms a high-temperature autoclaving environment, so as to 
promote the unhydrated cement particles forming more hydration product, provides fuller pozzolanic reaction and enhances the compressive strength of specimens [2].

The effect of increasing temperature on hydrated cement paste depends on the degree of hydration and moisture state. The presence of large quantities of evaporable water (free, capillary and adsorbed water as well as water from the cement hydration products) can cause shrinkage and damage to concrete in the form of surface spalling. The changes in the mass loss of fine-grained concrete are highly related to age of hardening (Fig. 3). Rapid water binding into hydration products in case of nanomodified concrete causes significant decrease in mass loss. It can be seen that changes in the mass loss of nanomodified concrete exhibited a mass loss 1.6-times lower after 1 day and 2-times lower after 7 days as compared to the samples of reference concrete.

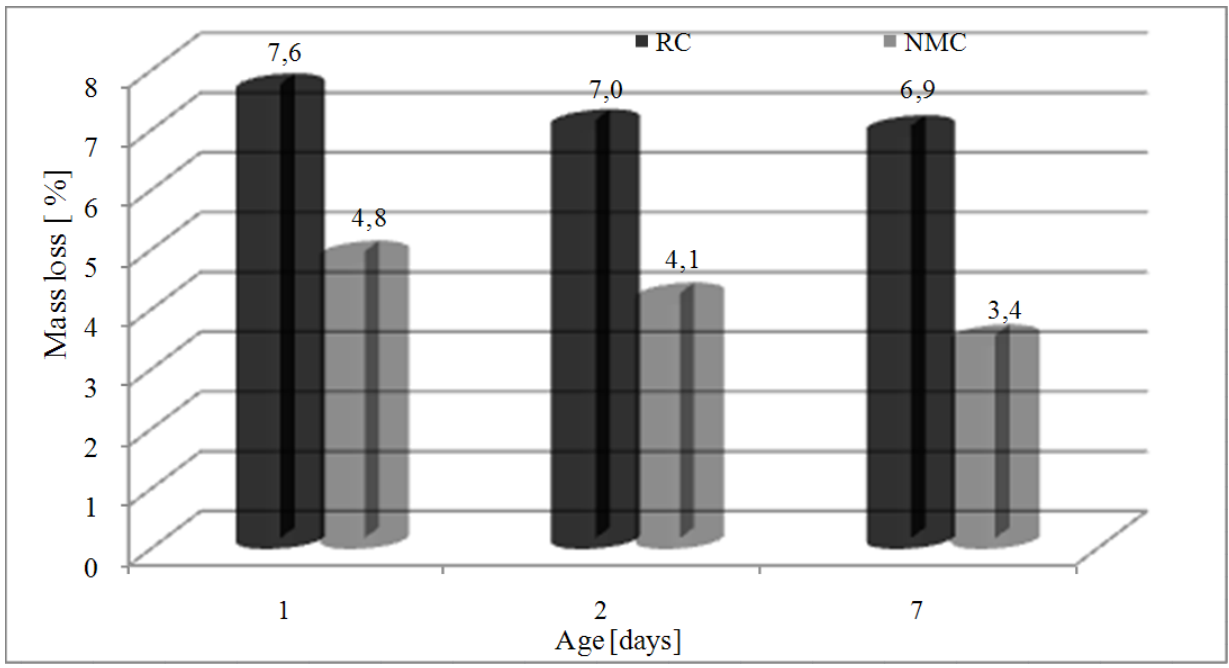

(a)

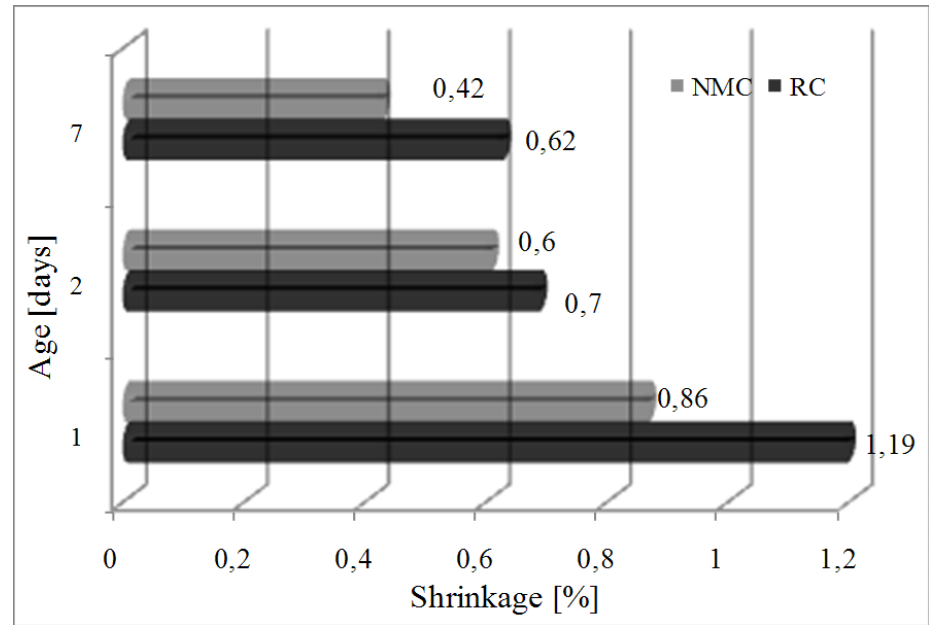

(b)

Fig. 3. Mass loss (a) and shrinkage (b) of fine-grained concrete exposure to $200{ }^{\circ} \mathrm{C}$.

A higher $\mathrm{w} / \mathrm{c}$ ratio increases the total shrinkage and the rate of shrinkage of the cement paste by providing more space for free water diffusion and reducing the rigidity of the solid matrix to resist deformation. Ultrafine additives densify the hydrated cementitious paste, 
thereby slowing down the rate of water evaporation and, hence, shrinkage. Thus, thermal shrinkage of nanomodified concrete after 1 day of hardening and exposure to $200^{\circ} \mathrm{C}$ is $0.86 \%$, which is $27.7 \%$ lower than the shrinkage of reference concrete.

\section{Conclusion}

The nanomodified concretes with ultrafine mineral additives are characterized by high strength at early and later age, exhibit enhanced stability of mechanical properties when exposed to temperatures in a range of 105 to $350^{\circ} \mathrm{C}$. The possibility of obtaining rapid hardening concretes with high thermal resistance is achieved by complex nanomodification with chemical admixture and ultrafine mineral additives, which is provided by water demand reducing, system particle packing optimization, increasing cement matrix density, stimulating nucleation processes in the intergranular space, acceleration of hydration process and pozzolanic reaction.

\section{References}

1. G. Wang, Ch. Zhang, B. Zhang, Q. Li, Z. Shui, Fire Mater., 39, 741 (2015)

2. C. Alonso, L. Fernandez, J. Mater. Sci. 39, 3015 (2004)

3. H.R Ashani, S.P. Parikh, J.H. Markna, Int. J. Nanosi. Ser., 2(5), 32 (2015)

4. U. Marushchak, M. Sanytsky, T. Mazurak, Yu. Olevych, Eastern Eur. J. Enterprise Technologies, 6 (84), 50 (2016)

5. P. Aggarwal, R.P. Singh, Y. Aggarwal, Cogent. Eng., 21078018 (2015)

6. E. Horszczaruk, P. Sikora, K. Cendrowski, E. Mijowska, Constr. Build. Mater., 137, 420 (2017)

7. J. Plank, C. Schroefl, M. Gruber, N. Lesti, R. Sieber, J. Adv. Concr. Technol., 7-1, 5 (2009) 